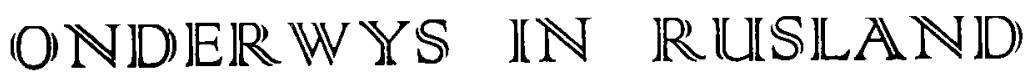

\author{
(vervolg)
}

\section{Die Onderwys in Rusland vanaf 1725 tot 1914}

5. Die Onderwys in Rusland na Peter die Grote tot die einde van die $19 \mathrm{e}$ eeu.

(a) Inleiding. Hoewel die groot massa van die Russiese volk na die omvorming deur Peter die Grote ongeletterd gebly het, het nuwe gesigspunte, nuwe gedragslyne, verligte idees by enkele geleerdes ontstaan. 'n Groter wisselwerking het geleidelik tussen Rusland en die Weste ingetree. Dit is ' $n$ erkende beginsel dat 'n nasionale stelsel van onderwys van 'n land sy ontstaan en ontwikkeling te danke het aan die goeie wat hy uit ander nasionale onderwysstelsels geneem het toe hy sy eie daaruit gebou het. So 'n nasionale onderwysstelsel van 'n land reflekteer die ,ethos" van 'n volk uit wie die stelsel gebore is en vir wie dit moet dien. Daarom word ' $n$ onderwysstelsel grootliks beïnvloed en sy karakter grootliks bepaal deur faktore en kragte buite die skool.

Langer kon Rusland nie geïsoleerd bly nie. Internasionale betrekkinge van Rusland en die ekonomiese verhoudinge het hom gedwing om 'n sosiale gedragslyn te volg wat sy ekonomiese posisie kan red. Die bevoorregte klasse sou nie langer die fort kan hou teen die nuwe idees en ideologie wat vinnig vir Rusland teen die einde van die 19e eeu oormeester laat nie. Die ou sosiale orde moet vir die nuwe plek maak. Om die groot agterstand op kulturele, sosiale en kommersiële gebied in vergelyking met die Westerse volke in te haal, moes noodwendig die rewolusie teen 1920 volg toe Rusland die leerstellinge van Marx in elke belangrike aspek van die Russiese lewe aanvaar het. Hoe anders en verskillend is die ideologie van Marx in vergelyking met die demokrasie van die Weste!

Geleidelik het daar verandering in die ou orde ingetree.

(b) Onderwys in Rusland vanaf $1725-1900$.

Alleen twee opvolgers van Peter die Grote het noemenswaardige belangstelling in die onderwys getoon.

Catharina II (1762-1796), wat o.a. met Rousseau se naturalisme en die verligte idees van Voltaire bekend geraak het, het 'n aantal onderwysteorieë daarop nagehou. Sy het geglo aan 'n verligte opvoeding van die toekomstige ouers en spesiale nadruk is op die opvoeding van dogters gelê. Dog diskriminering was onder die verligte despoot nog aan die orde van die dag. Net vir die kinders van die adel is voorsiening in koshuise gemaak. In haar onderwysprogram van 1782 is voorsiening vir 'n hoof-openbare skool in elk van die vernaamste stede, 'n klein openbare skool in die kleiner sentra en vier universiteite gemaak. As gevolg van finansiële tekorte het die plan in duie gestort. 
Die tweede regeerder wat meer as net 'n terloopse belangstelling in die ontwikkeling van bevoegde skole getoon het, was Alexander I in die begin van die 19e eeu (1801-1825). Hy het gesorg dat gedurende sy ampstermyn die onderwys nie net gratis sou wees nie, maar in sekere gevalle dat daar 'n geldelike toekenning aan leerlinge in hoërskole vir hul akademiese pogings toegeken word.

Alexander I se opvolger Nicholas I (1825-1855) was nie antagonisties teenoor die onderwys nie, maar het dit aangemoedig en 'n versigtiger beleid gevolg deur dit onder strenge kontrole te plaas. Maar nieteenstaande sy vrees het hy die werk van sy voorgangers voortgesit. Tegniese skole, militêre akademies en onderwyskolleges is geopen; kolleges vir vrouens is opgerig en spesiale skole is vir die adel ingerig. Kinders van handelaars en van die bourgeoise het spesiale skole, maar hulle is om verskillende redes ontmoedig om die klassieke skole by te woon. Dog baie van die Boerestand het deur die hunkering na kennis in die geselekteerde inrigtings ingesypel. Ontsteltenis het hieroor by die bevoorregte klasse ontstaan, met die gevolg dat dit tot onderdrukkende maatreëls gelei het. Groter beperkings is vir die klasse in die skoolwese gestel. Voortaan sou klas- of skoolgelde betaal moet word. Die vryheid van onderrig in die universiteite wat tot dusver gewaarborg was, is afgeskaf. Die dosering van Filosofie, wat helderheid van begrip gegee het, is as gevaarlik beskou. Gevolglik is dit ook oorboord gegooi. Militêre dissipline, wat waardevoller as filosofie beskou is, is in die plek daarvan in die universiteite en in die hoogste klasse van die sekondêre skole ingevoer. Dog oorvloedig was die reaksies onder sy regering. Met die kroning van Alexander II (1855-1881) is die sosiale orde, o.a. die opheffing van die lyfeigenes, aanmerklik verander. In 1861 is die lyfeigenes geëmansipeer. Staatkundige, regterlike en militêre hervormings het ook gevolg. Moderne drilmetodes is ingevoer en 'n deeglike uitgewerkte stelsel om ongeletterdheid uit te skakel, is toegepas. Alexander was liberaal in sy onderwysverbeteringe. Van die begin af het hy die meeste onderdrukkende maatreëls van sy voorganger afgeskaf. Die tradisionele universitêre onderwysvryheid is herstel. Die sekondêre skole is herorganiseer en natuurwetenskappe is by die leerplan gevoeg. Na die model van die ,real gymnasium" van Duitsland, wat Natuurwetenskappe benadruk, het hy sy ,real school" gestig. Voortaan sou alleen gegradueerdes van die klassieke sekondêre skool tot die universiteit toegelaat word. Behalwe die nuwighede is stappe ook gedoen om die onderwys vir dogters te verbeter, die skole minder selektief te omskep en meer aanpassend by die behoeftes van die dogters wat nis tot die adel behoort nie. In 1863 is skole vir die opleiding van onderwyseresse, 'n mediese skool vir vroue en 'n aantal primêre skole met 'n gewysigde en aangevulde leergang opgerig. Ongelukkig het die veranderinge soos deur die regeerders beoog met die primêre skool, net by die leergange gebly. Die gevolg was dat in die laaste twee dekades van die $19 \mathrm{e}$ eeu die Russiese onderwys die swakste was. 
6. Onderwys in Rusland in die begin van die 20e eeu tot 1914.

(a) Inleiding: In die vier eeue van Tsarisme is relatief baie min vir volksonderwys gedoen. Die hoër klasse, insluitende die Grieks-Ortodokse kerk, het gevoel dat te veel onderwys, selfs meer geletterdheid, gevaarlik vir die regering mag wees. In lyn met die tradisionele patroon was die Russiese onderwys egter op die hoë aristokratiese patroon van die vroeëre eeue gebaseer. Dit het beoog om onderwysvoordele byna uitsluitend aan die middel- en boonste klasse te gee.

(b) Laer Primêre Onderwys:

(i) Beheer en Administrasie.

Hoewel die Russiese skole onder staatsbeheer gestaan het, was net 'n klein hoeveelheid skole staatsondersteund. Was dit egter nie vir die inisiatief van provinsiale instellinge van selfregering nie, sou die onderhouding van die openbare primêre skool inderdaad onmoontlik gewees het. Dit is interessant om te weet dat die kerkskole, waarvan daar 'n groot aantal was, van staatsweë ondersteuning ontvang het, maar ook hulle was verder afhanklik van bykomstige plaaslike fondse. So is in 1905 vir plaaslike ondersteuning vir onderwys 10 miljoen roebels as addisionele steun gestem.

Teen 1914 was daar nog nie verpligte skoolbesoek nie, en die persentasie analfabete onder die Russiese volk was hoog.

Die laer onderwys het bestaan uit hoër- en laerskole, waarvan die grootste meerderheid hoërskole was. Terwyl hulle vry en gemengd was, het die pri-

KOERS mêre skole 'n driejarige kursus in party gebiede en ' $n$ vierjarige in ander gebiede aangebied. Die kinders van die Boereklas, verplig om hul ouers met die boerdery te help, het selde die skool die volle jaar besoek. Groot klasse van gemiddeld vyftig leerlinge per onderwyser is aangetref en soms het dit tot 70 en hoër gestyg.

\section{(ii) Leerstof.}

Die meeste laerskole se leerstof was die bekende drie, nl, lees, skryf, reken. Soms is aandag aan die grondbeginsels van Aardrykskunde en Geskiedenis bestee. As daar voldoende aanvraag was, is praktiese werk in tuinbou en naaldwerk ook by die daaglikse roetine gevoeg.

Godsdiensonderrig was verpligtend en die plaaslike priester het dan die Bybelse geskiedenis van die Ou en Nuwe Testament en die Geloofsbelydenis behandel. Die kinders is ook ingelei in kerksang, die belangrikste gebede en die Tien Gebooie.

Die kind het net één eksamen in sy hele laerskoolloopbaan afgelê en wel met skoolverlating, en dit het mondeling geskied. Waarskynlik was die grootste uitkoms vir 'n seun nie daarin geleë dat hy die laerskoolwerk voltooi het nie, maar in die feit dat die voltooiing van sy skooljare wesenlik sy tydperk van verpligte militêre diens verminder het.

(c) Hoër Primêre Onderwys: Hoër primêre onderwys het in die behoeftes van seuns op die platteland en in stede vir vyf of ses jaar voorsien. Die eerste twee jaar was effens meer as net die werk van die laer primêre skool. Gods- 
diens en lees, skryf en reken is weer ingesluit. As bykomstige vakke is Slawonies, elementêre Meetkunde, Geskiedenis, Aardrykskunde, Tekene, Skoonskrif, Fisika bygevoeg. Soms het handels- en tegniese vakke ook bygekom. Omdat die soort skole meeste in die groot stede gekonsentreer was, was hulle prakties vir die boerende kind onbereikbaar.

Die twee inrigtings, nl. die vry staatsprimêre en die kerk- of sinodeskool, waarvan die leerplanne groot ooreenkoms vertoon, is deur die Russiese jeug besoek. Natuurlikerwys het die kerkskool baie aandag aan godsdiensonderwys geskenk.

In die openbare staatskool het die personeel vir twee derdes uit vrouens bestaan met ' $n$ salaris van 30 roebels per maand met vry woonkamers, lig en brandstof. Elke vyf jaar was die salarisverhoging 5 roebels per maand en die maksimum loon het nie 50 roebels per maand oorskry nie. $\mathrm{Na} 25$ jaar diens was die onderwyser op 'n pensioen gelykstaande aan sy maandelikse salaris geregtig.

(d) Sekondêre Onderwys. (i) Algemeen.

Ooreenstemmend met die heersende sekondêre onderwys van die groot moondhede in Wes-Europa het die Russiese onderwys dieselfde leemte geopenbaar omdat dit nie aan die elementêre onderwys gebind was nie.

Net soos die sekondêre skole van Frankryk, Duitsland e.a. was die van Rusland net vir die elite beskore. In toevoeging tot die klassieke gimnasium was daar die „real school" te vinde wat 'n uitvloeisel was van die wetenskaplike skole wat tydens die regering van Alexander II gestaak is.

(ii) Beheer van die Sekondêre Onderwys: Die Gimnasium en "real school" is deur die Minister van Openbare Onderwys beheer, terwyl die Godsdiensof Kerkskool en seminarium deur die kerk en die militêre kosskool of kadetskool deur die Oorlogskantoor beheer en geadministreer is.

Afgesien van die feit dat die Gimnasium of deur die staat of private inisiatief onderhou is, is skoolgelde geeis, maar alleen $15 \%$ van die studente hei gratis onderwys ontvang. Die meerderheid van die studente in die Gimnasium is deur seuns van die professionele of amptenaarsklas in die staatsdiens uitgemaak. In die Gimnasium was die lengte van die kursus 8 jaar en 7 jaar in die ,real school", beginnende by 10 jaar.

(iii) Leervakke: Die leervakke in die Gimnasium was Bybel, Russies, Slawonies, Latyn, Grieks, Matesis, Fisika, Geskiedenis, Aardrykskunde, of Frans of Duits, Skoonskrif, Tekene, Logika. In die „reàl school" is geen klassieke tale gegee nie, maar moderne tale was verpligtend. In die tipe skole is meer tyd aan Matesis en Fisika en minder tyd aan Geskiedenis en Letterkunde bestee. In party "real schools" is die studente toegelaat om in die hoogste klasse handelsvakke te kies.

Vry onderwys is in die kerkskole en seminarium ontvang, hoewel ander leerlinge van wie skoolgeld gehef word, ook toegelaat is: 'n Sesjarige kursus wat deur ' $n$ vierjarige voorbereidende kursus voorafgegaan word, is by die semina- 
rium aangebied. In die twee inrigtings word teologie bestudeer vir die voorbereiding tot leraars.

Die Kadetskole met 'n sewejarige kursus is militêre instellinge vir seuns wat begerig is om hulle vir militêre diens of vir hoër militêre kolleges te bekwaam. Die leerstof van die skole vertoon groot ooreenkoms met die ,real schools". Alle onderrig word deur die militêre owerheid gegee.

Van al die skole kwalifiseer die Gim. nasium alleen vir toegang tot die universiteit. Die diploma van die „real schools" bied opening tot die hoër tegniese skole. Graduering in die Gimnasium en „real school" verminder die tydperk van verpligte militêre diens tot één jaar.

(iv) Administrasie van die Onderwys.

Groot ooreenkoms bestaan daar in die administrasie van die Gimnasium en "real school". Beide het 'n direkteur aan die hoof wat deur die kuratorium van die distrik benoem is, en hy is deur 'n inspekteur van onderwys bygestaan om die ampspligte te vervul. Die onderwysers, wat ook deur die kuratorium benoem is, moet 'n universiteitsgraad of 'n kwalifikasie gelykstaande daaraan besit en is teen ' $n$ salaris van $\mathbf{1 8 0 0 - 2 2 0 0}$ roebels per jaar benoem.

Die onderwysers in die staatskole is as staatsamptenare beskou. Teoreties is hul van militêre diensplig vrygestel, maar dit is nie altyd konsekwent deurgevoer nie. Net soos onderwysers in die laerskole, ontvang die onderwysers in die sekondêre skole ook 'n pensioen na 25 jaar diens.

(e) Sekondêre Onderwys vir dogters. Sekondêre onderwys vir dogters voor
1914 is gegee in inrigtings soos kosskole, gimnasia en domskole. Net soos vir die seuns van die ryk middelklasse, is vir dogters van die klasse 'n sewetot agtjarige kursus aangebied. Die gimnasia was dagskole wat deur die staat of private donateurs geldelik ondersteun is.

Die domskole was 'n dagskool wat 'n sewejarige kursus vir dogters van geestelikes aangebied het, maar dit was vir alle klasse studente oop. Net soos die seminaria en kerkskole vir seuns, is die domskole hoofsaaklik deur lokale fondse instand gehou. Graduering in enige een van die drie tipe skole het so 'n student gekwalifiseer om onderwys in die primêre skool te gee. Om sekondêre onderwys te gee deur dogters, is hoër kwalifikasies vereis. Die leerplan van die dogterskole was as geheel dieselfde as dié van die seunskole, maar opvallend is die gemis aan klassieke tale in die leerplan van die dogters. Tyd is gewy aan spesiale onderwerpe soos naaldwerk, onderwyspraktyk, e.d.m.

Apart van die algemene soorte sekondêre skole was daar 'n aantal wat spesiale aandag gegee het aan die opleiding van primêre onderwysers en die voorbereiding van mediese assistente.

(f) Tegniese en Handelskole voor die uitbreek van die Eerste Wêreldoorlog.

Teen die einde van die regering van Nicholas II, die laaste Tsaar van Rusland, is voorsiening vir tegniese en handelskole gemaak. Hoewel dit ontoereikend was, het die tipe skole vinnig toegeneem. Daar was sowat 200 skole 
wat 'n drie- of vierjarige kursus in die opleiding van ambagsmanne aangebied het. Dit was oop vir alle volwassenes wat in fabrieke vir ten minste twee jaar gewerk het en ook vir seuns tussen 11-15 jaar wat die laerskoolkursus deurloop het. Daar was ook 'n paar hoër tegniese skole bestemd vir die opleiding van ingenieurs en aptekers. Sulke skole was alleen bedoel vir graduandi van Gimnasiums en ,real schools”.

Die handelskole was aan regeringskontrole onderworpe en deur plaaslike fondse onderhou. Vir hierdie twee redes was dit net soos enige ander skool in tsaristiese Rusland afhanklik.

Die handelsonderwys het in viersoortige inrigtings geskied: handelskole, sakeskole, handelsklasse en kursusse in handelskennis.

Handelskole het 'n sewejarige kursus aangebied en groot ooreenkoms is met die werk in die ,real schools" getoon, maar gedurende die laaste twee jaar van die kursus is veral op handelsopleiding gekonsentreer. Die kursus was hoofsaaklik bestemd vir daardie studente wat na die tegniese hoërskool wou gaan.

Die sogenaamde sakeskole was bedoel vir klerke en kantoorwerkers. Primêre onderwys was 'n vereiste tot toelating.

Handelsklasse is gewoonlik in die aande gehou en dit was hoofsaaklik vir kantoorwerkers bedoel. So 'n kursus was baie elementêr en gewoonlik nietegnies van aard. Die mees gevorderde soort van handelsonderrig vir handelskennis is in die kursus aangebied. Vir die doel om onderwysers op te lei vir handelsvakke, het hierdie kursus gevor- derde onderwys in spesiale rigtings aangebied. Die kursus was oop vir almal wat sekondêre onderwys ontvang het.

7. Die stand van die Onderwys teen 1914.

Met die opkoms van die nywerhede in Rusland teen die einde van die 19e eeu is baie meer skole in die algemeen geopen. Die rewolusie van 1905 het aansienlike onderwysveranderinge teweeggebring.

In die begin van die $20 \mathrm{e}$ eeu tot met die uitbreek van die Eerste Wêreldoorlog was dit vir Rusland gebiedend noodsaaklik om baie meer pogings aan die dag te lê om die onderwys te verbeter. 'n Hele omvorming en verandering van beleid het ingetree. Waar landbou tot die einde van die $19 \mathrm{e}$ eeu die vernaamste onderneming in Rusland was, is na ' $n$ beleid van industrialisasie oorgeskakel. So snel het die produksie toegeneem dat teen 1906 Rusland byna al die material vir sy spoorweguitbreiding gelewer het. Hiervoor het die industrieland tegnici nodig gehad om die fabriekswiele te laat rol. In die toekoms was meer mannekrag nodig en daarby geskoolde manne in die verskeie beroepe. Teen 1908 is groot toegewings vir elementêre onderwys gemaak, met die gevolg dat die laerskole snel toegeneem het. Teen 1914 was daar 6 miljoen skoolgaande kinders, meer as 100,000 vry primêre skole, sowat 1600 intermediêre en 2500 sekondêre skole. 2800 beroepskole het ' $n$ miljoen kinders opleiding verskaf met uitsondering van die groot aantal handelstudente in die bogenoemde inrigtings. 
Rusland het 'n gesentraliseerde onderwysstelsel wat uitwendig die stempel van doeltreffendheid besit, maar by noukeurige ondersoek sal baie van die lofwaardige kenmerke van die onderwys in die lug verdwyn. Klassebevoorregting, seleksie en geen verpligte onderwys om analfabetisme te bekamp, het tot nadeel gewerk.

Die heengegane keiserryk het vir elementêre opvoeding voorsiening gemaak. Sekondêre onderwys was net vir 'n geselekteerde groep. Die kloof tussen primêre en sekondêre onderwys was dieper en wyer in Rusland as in Frankryk en Duitsland. In die lg. twee lande het die primêre onderwys gedien as grondslag vir die fundamentele begrippe wat angeletterdheid redelik goed kon verhoed. Dit is beweer dat in Rusland nie alleen ongeletterdheid gefloreer het nie, maar dat die staat min gedoen het om die onderwys te stimuleer. Alles is in sy mag gedoen om die werk van verligting te verhinder. Die Russiese onderwys was die beliggaming van die beginsel soos dit deur die Minister van Onderwys, Shisktov, gedurende die regering van Alexander I geformuleer is: om die massa te onderrig of selfs die meerderheid van die volk te leer, sal meer nadeel as voordeel bring.

In een opsig, egter, was die onderwysmanne van die Tsaristiese regime behoorlik bevoeg. Bekend met die fynste besonderhede, met die ingewikkeldhede van die burokrasie en gekonfyt in die beginsels van spioenasie, het die swerm goewermentsinspekteurs hulle here goed gedien. Haat en nyd het by baie onderwysers teenoor die amptenare ontstaan. Tydens die aftakeling van die uitgewerkte onderwysmasjien deur die kommuniste, moes die ministeriële inspekteurs die eerste die wyk neem.

Vanaf 1917 is tot 'n universele onderwysbeleid oorgegaan. Algehele verpligte volksonderwys is ingestel maar een groot leemte is dadelik bespeur: geen spoor van Godsdiens is in die leerplan gevind nie. Natuurwetenskappe het die wagwoord en die Bybel van die Rus geword. Tegnoloë moet Rusland op industriële en op wetenskaplike gebied die demokratiese Weste laat verbystreef. Vir die Marxistiese ideologie moet die hele Russiese volk geïndoktrineer word.

\section{J. J. SNIJMAN.}

P.U. vir C.H.O. 